\title{
COMPARISON OF ROSUVASTATIN AND ATORVASTATIN IN ACHIEVING THE TREATMENT GOALS OF DYSLIPIDEMIA
}

\author{
Naresh Jyoti, Poonam, Jaswant Rai, Sharanjit Kaur, Ashok Dhillon
}

1. Assistant Professor, Department of Pharmacology, Chintpurni Medical College \& Hospital, Pathankot (Pb.)

2. Associate Professor, Department of Anatomy, Chintpurni Medical College \& Hospital, Pathankot (Pb.)

3. Prof \& Head, Department of Pharmacology, Government Medical College, Amritsar (Pb.).

4. Assistant Professor, Department of Pharmacology, Chintpurni Medical College \& Hospital, Pathankot (Pb.)

5. Senior Resident, Department of Medicine, Chintpurni Medical College \& Hospital, Pathankot (Pb.)

\section{CORRESPONDING AUTHOR}

Dr. Naresh Jyoti,

Asst. Professor, Department of Pharmacology,

Chintpurni Medical College \& Hospital,

Pathankot (Pb.).

E-mail: nareshdel@yahoo.com

Ph: 00919779115349

ABSTRACT: CONTEXT (BACKGROUND): Dyslipidemia has been recognized as main reason for development of atherosclerosis and coronary artery disease. Statin group of drugs are most commonly prescribed for the treatment of dyslipidemia. Among them atorvastatin and relatively new drug rosuvastatin are prescribed more frequently. AIM: The aim of the study was to compare effectiveness of rosuvastatin and atorvastatin in dyslipidemia and achieving the treatment goals set by ATP III and Asian Indian Guidelines. SETTING AND DESIGN: This 12 weeks, open label, randomized study was conducted at the Department of Pharmacology and Medicine, Government Medical College, Amritsar (Punjab), India. METHODS AND MATERIAL: Patients aged $30-70$ years with dyslipidemia were eligible. Patients were assigned one of two treatment groups. Group I received atorvastatin and group II received atorvastatin. Both drugs were given in dose $10 \mathrm{mg} / \mathrm{d}$ for 12 weeks. The lipid profile low density lipoprotein cholesterol (LDL-C), high density lipoprotein cholesterol (HDL-C), total cholesterol (TC), non-high density lipoprotein cholesterol (non HDL-C), triglycerides (TG) and very low density lipoprotein cholesterol (VLDL-C) were measured before the start of therapy and after 12 weeks. Percentage changes from baseline were calculated and adverse effects were recorded. STATISTICAL ANALYSIS USED: Paired Student's' $t$ ' test was applied within the group after treatment interval and unpaired' $t$ ' test is applied when 2 groups are compared. RESULTS AND CONCLUSIONS: Sixty patients ( 31 men, 29 women) were enrolled; 30 patients per treatment group. In group I, mean percentage decrease in levels of TC, LDC-C, non-HDL-C, TG and VLDL-C were $28.15 \%$, $30.77 \%, 37.28 \%, 50.75 \%$ and $50.75 \%$ respectively whereas mean percentage increase in HDL-C was $32.15 \%$ at 12 weeks. In group II, mean percentage decrease in levels of TC, LDC-C, nonHDL-C, TG and VLDL-C were 42.26\%, 49.03\%, 51.15\%, 60.91\% and 60.91\% respectively whereas mean percentage increase in HDL-C was 29.26\%. Myalgia, nausea, vomiting and headache were the adverse effects observed in both groups. Rosuvastatin is more effective than atorvastatin in achieving the targets of TC (100\% vs $96.66 \%)$, LDL-C (100\% vs $53.33 \%)$ set by ATP III guidelines and targets of TC (73.33\% vs $6.66 \%)$, LDL-C (66.66\% vs $3.33 \%)$ respectively set by Asian Indian guidelines.

KEY WORDS: atorvastatin, rosuvastatin, dyslipidemia, treatment goals 
INTRODUCTION: Dyslipidemia has been recognized as the foundation for atherosclerosis and development of coronary artery disease. The risk of CAD in Indians is 3-4 time higher than White Americans, 6 times higher than Chinese and 20 times higher than Japanese.1,2

The United States National Cholesterol Education Programme-Adult Treatment Panel has issued guidelines from time to time to manage dyslipidemia so as to decrease the incidence of CAD. These guidelines based on the prevalent dyslipidemic picture in the population help to define the treatment goals in patients by setting the desired values for the various lipid profile parameters. The latest report of adult treatment panel (ATP III) focuses on primary prevention of dyslipidemia in persons with multiple risk factors. ${ }^{3}$

These guidelines are more applicable to the western population and are not suited for the Indian population as the latter has a different lipid profile and risk factors. ${ }^{4}$ Incidence of CAD among Asian Indian is 3-4 times higher than the white population..$^{\mathbf{5}}$ In the Indian population, more strict control of lipid profile is needed. The new goals are proposed for Asian Indians which are more strict. These goals are modified from NCEP 164 report and values are about $20 \%$ less than ATP III guidelines. ${ }^{6}$ (Table I)

The initial approach to a patient of dyslipidemia is modifications in life style i.e. diet modification (low fat consumption), weight loss, physical activity, smoking cessation, aggressive control of diabetes and hypertension. If these changes do not suffice then pharmacotherapy has to be implemented. The drugs available for use are HMG-CoA reductase inhibitors, nicotinic acid, bile acid sequestrants, fibric acid derivatives and probucol. In addition to these there are indigenous drugs ${ }^{7,8}$ like husk of Plantgo ovata (Ispaghula husk), Trigonella foenumgraecum seeds (Fenugreek) etc.

Out of these drugs, simvastatin and atorvastatin are commonly prescribed drugs for dyslipidemia. Rosuvastatin is a relatively newer member of statins which is more expensive than existing members of statins and its prescription is also on the rise. That is why in the present study rosuvastatin has been included. Atorvastatin has been taken as a standard drug due to the fact that it is more frequently and has been reported to be better drug in dyslipidemia over other members of statin group. All of these factors have formed the basis of present study in which effect of rosuvastatin and atorvastatin on lipid profile has been compared in addition to their safety in dyslipidemic patients.

AIMS AND OBJECTIVES: The purpose of this study is to compare the effect of rosuvastatin and atorvastatin on lipid profile in non- diabetic dyslipidemia in achieving the goals as per ATP III and Asian Indian Guidelines.

MATERIAL AND METHODS: The plan of the study was submitted to the Institutional EthicsCommittee and approval was sought. After the approval of the Ethics Committee, patients were recruited from Medicine Department of Guru Nanak Dev Hospital, Amritsar in the age group of 30-70 years. A total 60 patients were enrolled for the study.

SELECTION CRITERIA: A total of 60 patients within the age group of 30-70 years with abnormal lipid profile (serum total cholesterol $>200 \mathrm{mg} \%$, LDL-C $>100 \mathrm{mg} \%$ or HDL-C $<35$ mg\%) attending Medical OPD/Ward of Guru Nanak Dev Hospital attached to Government Medical College, Amritsar were enrolled in study. The consent of the patients was obtained after fully explaining the details of study procedures to them. 


\section{DRUGS TO BE INVESTIGATED}

1. Tab Rosuvastatin $10 \mathrm{mg}$ once daily.

2. Tab Atorvastatin $10 \mathrm{mg}$ once daily.

Each of these was given for 12 weeks

\section{EXCLUSION CRITERIA:}

Patients are excluded from the study if they are:

1. Hypersensitive to rosuvastatin or atorvastatin.

2. Having diabetes mellitus/ hypothyroidism/ nephrotic syndrome/ Gout/pancreatitis / uncontrolled hypertension.

3. Pregnant and lactating women.

4. Women on oral contraceptive pills (OCPs) estrogen/hormone replacement therapy.

5. Having history of muscle pain (fibromyalgia with associated raised CPK levels.

6. Patients with abnormal liver function test (LFT) and renal function test (RFT).

7. Concurrently using of Cyp 3 A4 isoenzyme i.e. azole antifungals, macrolides, calcium channel blockers (except dihydropyridines e.g. nifedipine, amlodipine), cyclosporine, histamine-2 blockers, grape fruit juice and enzyme inducers like phenobarbitone, rifampicin, phenytoin, carbamazepine.

DESIGN OF THE STUDY: The study was a randomized, open label, and parallel study. In this study after getting initial baseline, overnight fasting lipid levels at the start (week 0) of the study, and subsequent levels were obtained at $12^{\text {th }}$ week of the study.

After enrollment history of patients was taken and physical examination was done. Total 60 patients were divided randomly into two groups of 30 patients each and assigned as group I and Group II. Group I received atorvastatin (10 mg tablet OD) and Group II received rosuvastatin (10 $\mathrm{mg}$ tablet $\mathrm{OD}$ ) for 12 weeks. In both the groups, patients were instructed to take drug 30 minutes before evening meal.

The patients were advised to continue with their dietary modification and physical activity and they were explained the schedule of the drug treatment. The patients were also advised to report immediately in case they developed unexplained muscle pain/undue tiredness, low urine output or any other symptoms pertaining to side effects of the drugs. At the end of the study, the patients were kept under regular follow up to monitor adverse events for additional 6 weeks with the Department of Pharmacology and Medicine, Government Medical College, Amritsar.

PARAMETERS AND LABORATORY PROCEDURES: The study was conducted by initially recording the baseline investigations in each patient and subsequently doing investigations at $12^{\text {th }}$ weeks. The patients were also instructed to visit the hospital at 6 weeks to monitor any adverse reaction or to report any time in case of adverse event. The history of the patient, clinical examination and adverse events were recorded on each patient visit and blood samples were drawn for estimation of lipid profile at 0 week and $12^{\text {th }}$ week after overnight fasting for 12 hours.

The investigations were carried out in the Department of Pharmacology using proprietary kit methods. The instrument used for analysis of blood samples was spectrophotometer. After taking samples the serum was assayed with the help of a centrifuge machine by rotating it at 2000 revolutions per minute, for 10 minutes at $37^{\circ} \mathrm{C}$ and serum was used to determine TC levels followed by HDL-C levels after precipitation of VLDL-C and LDL-C. 
Blood samples were analysed using a spectrophotometer by CHOD/POD-phosphotungstate method. ${ }^{9}$

Very low density lipoprotein Cholesterol (VLDL-C) was calculated by formula ${ }^{10}$

$$
\text { VLDL-C }=\frac{\text { Triglycerides }}{5}
$$

Low density lipoprotein cholesterol (LDL-C) ${ }^{10}$ was calculated by using Friedewald's formula

$$
\text { LDL-C }(\mathrm{mg} / \mathrm{dl})=\text { T.C }(\mathrm{mg} / \mathrm{dl})-\mathrm{HDL}-\mathrm{C}(\mathrm{mg} / \mathrm{dl})-\frac{\text { Triglycerides }}{5}
$$

Non-HDL-C was calculated by: TC - HDL-C

STATISTICAL ANALYSIS: Data generated from the study was evaluated and expressed as mean \pm SD of each variable. Paired Student's't' test was applied within the group after treatment interval and unpaired ' $t$ ' test was applied when 2 groups were compared.

OBSERVATIONS AND RESULTS: The observations were tabulated as mean \pm standard deviation and analysis was done using student's' $t$ ' test and level of significance was determined by its 'p' value. ' $p$ ' value $<0.05$ was taken as statistically significant.

DISCUSSION: Clinically dyslipidemia is presented by levels of TC $>200 \mathrm{mg} / \mathrm{dl}$, LDL-C $>100 \mathrm{mg} / \mathrm{dl}$, $\mathrm{TG}>150 \mathrm{mg} / \mathrm{dl}$ and HDL-C $<40 \mathrm{mg} / \mathrm{dl}$ in a patient with CAD. In non-CAD patients, the levels of these parameters are determined by presence of one or more risk factors. Dyslipidemia is one of the major risk factor for the causation of CAD and the aim of drug therapy for dyslipidemia is to bring the levels of these parameters in desirable range. Presently statins are the commonly prescribed drugs for the treatment of this disorder.

In various comparative clinical studies11,12,13,14,15 atorvastatin has been proved to be better than simvastatin which has been claimed to be a better agent than the existing members of the family.

In the present study, atorvastatin and rosuvastatin, both HMG-CoA reductase inhibitors have been studied as monotherapy in the patients of dyslipidemia.

Both these drugs have been shown to exert its major effect on lowering of serum TC and LDL-C levels.

Group I and Group II with 30 patients each participated in the study with average age for group I being, $54.9 \pm 11.42$ years and for group II $52.33 \pm 8.43$ years.

The mean serum total cholesterol levels at the beginning of the study were $241.62 \pm$ $29.57 \mathrm{mg} / \mathrm{dl}$. These levels were significantly higher than the mean TC levels of $157 \pm 29 \mathrm{mg} / \mathrm{dl}$ as reported by Gandhi ${ }^{16}$, in a study of 201 healthy urban Delhi subjects. These levels were also higher than the levels as reported by Gopinath et al17 in patients of CAD who had reported values of $210 \mathrm{mg} / \mathrm{dl}$ and $169 \mathrm{mg} / \mathrm{dl}$ in urban and rural area respectively.

The mean levels of serum HDL-C reported at the beginning of the study were $31.63 \pm 5.9$ $\mathrm{mg} / \mathrm{dl}$. These levels were lower than the levels reported by Gopinath et al ${ }^{17}$ who reported serum HDL-C of $56 \pm 13 \mathrm{mg} / \mathrm{dl}$ in urban and $51 \pm 9 \mathrm{mg} / \mathrm{dl}$ in rural subjects and levels reported by Gupta et al ${ }^{18}$ who reported higher levels in rural men as compared to urban men $(44.0 \pm 13 \mathrm{vs}$ $43.1 \pm 12 \mathrm{mg} / \mathrm{dl})$

The mean serum LDL-C levels and TG levels at initiation of the study were $145.19 \pm$ 24.89 and $325.91 \pm 88.55 \mathrm{mg} / \mathrm{dl}$ respectively. Mean VLDL-C levels reported at the beginning of the study $65.18 \pm 17.7 \mathrm{mg} / \mathrm{dl}$. 
GROUP I: In the present study atorvastatin $10 \mathrm{mg} /$ day for 12 weeks resulted in statistically significant fall in levels of serum TC and LDL-C by $28.15 \%$ and $30.77 \%$ (Table IV). This fall was lower than $33 \%$ and $42 \%$ as reported by Noseda et al ${ }^{19}$ with $10 \mathrm{mg}$ /day of atorvastatin at 12 weeks. This fall is almost similar to the fall reported by Mckenney et $\mathrm{al}^{\mathbf{2 0}}$ who reported fall of $26 \%$ and $30 \%$ for serum TC and LDL-C with use of atorvastatin $10 \mathrm{mg}$ /day for 12 weeks.

Atorvastatin decreased the serum TG by $50.75 \%$ in 12 weeks which significantly more than $25 \%$ decrease in serum TG after 12 weeks use of atorvastatin as reported by Tiek C. Ooi et al. ${ }^{21}$

On analysing the effect of atorvastatin on serum VLDL-C, it was found that serum VLDLC decreased by $50.75 \%$ at 12 weeks. This fall at 12 weeks was higher than the fall as reported by Tiek C. Ooi et al ${ }^{21}$ who reported a fall of 35\% in VLDL-C levels after 12 weeks administration of atorvastatin $10 \mathrm{mg} /$ day.

The rise in levels of serum HDL-C by atorvastatin at the end of 12 weeks was $32.15 \%$. This rise is significantly more than $10 \%$ as reported by Frost et al. ${ }^{22}$

GROUP II: The levels of serum TC and LDL-C are decreased by $42.26 \%$ and $49.03 \%$ respectively with the use of rosuvastatin after 12 weeks (Table IV). This fall in TC is more than the fall reported by Blasetto et al ${ }^{23}$ who reported a fall in TC by $34 \%$. But fall in LDL-C is almost similar to $48.1 \%$ as reported by Blasetto et $\mathrm{al}^{23}$ and $48 \%$ as reported by Ballantyne et al. ${ }^{24}$

On analyzing the effect of rosuvastatin on levels of TG and HDL-C, an extremely significant fall of $60.91 \%$ in TG levels and rise of $29.26 \%$ in HDL-C levels was reported after 12 weeks. This change in levels was significantly higher than $28.8 \%$ and $12.9 \%$ respectively as reported by Blasetto et $\mathrm{al}^{23}$ who also stated that patients with elevated TG appeared to have greater percentage decrease in TG levels and greater percentage increase in HDL-C than do those with lower TG. This change in levels of TG and HDL-C was also significantly higher than $23 \%$ and $10 \%$ respectively as reported by Ballantyne et al. ${ }^{24}$

SAFETY PROFILES: Both drugs were well tolerated. Nausea/vomiting, headache and myalgia (mild muscle pain) were reported in few patients in both groups but difference was not significant. Apart from these, no other side effect was noticed in 12 weeks of the study.

GOALS ACHIEVED AFTER 12 WEEKS: The goals achieved after 12 weeks of treatment, were compared with ATP III and Asian Indian Guidelines.

It was seen that in Group I, 96.66\% of patients achieved TC target while 53.33\% of patients achieved LDL-C target set by ATP III guidelines. In group II, 100\% patients achieved both TC and LDL-C targets set by ATP III (Table V).

On the other hand when values at 12 weeks were compared with Asian Indian Guidelines it was found that in group I, 6.66\% of patients achieved TC target and 3.33\% achieved LDL-C target considered to be desirable by Asian Indian Guidelines (Table VI).

In group II, $73.33 \%$ of patients achieved TC target and $66.66 \%$ of patients achieved LDLC goal set by Asian Indian Guidelines.

So it is clear that in group II more patients achieved ATP III and Asian Indian Goals as compared to Group I after 12 weeks of treatment.

REASON FOR BETTER EFFICACY OF ROSUVASTATIN: Rosuvastatin is a significantly more potent blocker of hepatocyte sterol than all other statins currently available. It differs 
structurally from other statins, containing a polar methane sulphonamide group which confers relative hydrophilicity, which in turn imparts greater selectivity for uptake into hepatic versus non- hepatic cells. ${ }^{25}$

CONCLUSION: Rosuvastatin had an overall better effect on lipid profile than atorvastatin. It lowers serum TC, LDL-C, TG and VLDL-C to significantly greater extent than atorvastatin but its efficacy is equal to atorvastatin when change in HDL-C levels is considered. Rosuvastatin is more effective than atorvastatin in achieving the targets of TC (100\% vs $96.66 \%)$, LDL-C (100\% vs $53.33 \%$ ) set by ATP III guidelines and targets of TC (73.33\% vs $6.66 \%)$, LDL-C (66.66\% vs $3.33 \%$ ) respectively set by Asian Indian guidelines. It can be concluded that rosuvastatin is more effective in achieving guidelines goals as compared to atorvastatin.

From these observations it can also be concluded that atorvastatin can be recommended in mild or borderline cases whereas rosuvastatin in patients with high and very high lipid levels.

Multiple studies across the country taking into consideration the ethnic, dietary, genetic and cultural variability are needed in establishing the validity and relevance of these observations and recommendations.

\section{REFERENCES:}

1. Enas EA, Garg A, Davidson MA et al. Coronary heart disease and its risk factors in the first generation immigrant Asian Indians to United States of America. Indian Heart J. 1996; 48:343-54.

2. Enas EA. High rates of CAD in Asian Indians in the United States despite intensive modification of life style. What next. Current Science 1998;74.

3. ATP-III Report. Executive summary of the third report of the National Cholesterol Education Programme Expert Panel on Detection, Evaluation and Treatment of high blood cholesterol in adults. JAMA. 2001;285:2486-2487.

4. Enas EA, Yusuf S, Mehta JL. Prevalence of coronary artery disease in Asian Indians. Am J Cardiol. 1992;70:945-949.

5. Hughes LO, Ravel U, Raftery EB. First myocardial infarction in Asian and Whitemen. Br Med J. 1989;298;1345-1350.

6. Enas E, Senthikumar A. Coronary for Prevention of Hypertesnion and Coronary Artery Disease. Indian J Cardiol. 1998; 15: 57-62.

7. Prasanna M. Hypolipidemic effect of Fenugreek: A clinical study. IJP. 2000;32:34-36.

8. Anderson JW, Allgood LD, Turner J, Deltgel PR, Daggy BP. Effect of Psyllium on glucose and serum lipid responses in men with Type 2 diabetes and hypercholesterolemia. Am J Clin Nutr. 1999;70:466-474.

9. Allain CC, Poon LS, Chan CSG, Richmond W. Enzymatic determination of total cholesterol. Clin Chem. 1974;29:470-474.

10. Friedwald WT, Levy RI, Frederickson DS. Estimation of concentration of low density lipoproteins cholesterol in plasma without use of the preparative centrifuge. Clin Chem. 1972;18:499-502.

11. Jones PH, Davidson MH, Stein EA, Bays HE, McKenney JM, Miller E, et al. Comparison of the efficacy and safety of rosuvastatin versus atorvastatin, simvastatin and pravastatin across doses (STELLAR TRIAL). Am J Cardiol. 2003;92(2):152-160.

12. Schuster H, Barter PJ, Stender S, Cheung RC, Bonnet J, Morrell JM, et al. Effects of switching 
statins on achievement of lipid goals: Measuring effective reductions in cholesterol using rosuvastatin therapy (MERCURY I study). Am Heart J. 2004;147(4):705-713.

13. Stalenhoef AFH, Ballantyne CM, Sarti C, Wilpshaar W, Southworth H, Tuomilehto, et al. Comparative study with rosuvastatin in subjects with metabolic syndrome. Expert Opin Pharmacother. 2004;5:1187-1200.

14. Strandberg TE, Feely J, Siqurdsson EL. Twelve Week, multicentrer randomized open label comparison of the effects of rosuvastatin $10 \mathrm{mg} / \mathrm{dl}$ and atorvastatin $10 \mathrm{mg} / \mathrm{d}$ in high risk adults: a DISCOVERY study. Clin Ther. 2004;26(11):1821-1833.

15. Berne C, Siewert DA. Editors. Use of rosuvastatin versus atorvastatin in type 2 diabetes mellitus subjects: results of the URANUS study. Proceedings of the 74th European Atherosclerosis Society Congress; 2004 April; Seville, Spain; 2004.

16. Gandhi BM. Lipoprotein composition of normal healthy subjects in Northern India. Indian J Med Res. 1982;75:393-401.

17. Gopinath N, Chadha SL, Sehgal A, Shekhawat S, Tandon R. What is desirable lipid profile. Indian Heart J. 1994;46:145-150.

18. Gupta R, Praksh H, kaul V. Cholesterol lipoproteins, triglycerides, rural-urban difference and prevalence of dyslipidemias among males in Rajasthan. J Assoc Physicians India. 1997;45:272-279.

19. Noseda G, Darioli R, Keller U, Mordasini R, Shokry A, Schaffhauser B, et al. Evaluating the efficacy and tolerance of atorvastaitn in hyperlipidemia in general practice (SWITCH Study). Schweiz Med Wochenschr. 2000;130(23):889-895.

20. Mckenney JM, McCormick LS, Weiss S, Koren M, Kafonek S, Black Diabetes Mellitus. A randomized trial of the effects of atorvastatin and niacin in patients with combined hyeprlipdiemia or isolated hypertriglycerdiemia. Am J Med. 1998;104(2):137-143.

21. Ooi TC, Heinonen T, Alaupovic P, Davignon J, Leiter L, Lupien PJ et al. Efficacy and Safety of a New Hydroxymethylglutaryl-Coenzyme A Reductase Inhibitor, Atorvastatin, in Patients with Combined Hyperlipidemia: Comparison with Fenofibrate. Arteriosclerosis, Thrombosis, and Vascular Biology.1997;17:1793-1799.

22. Frost RJ, Otto C, Geiss HC, Schwandt P, Parhofer KG. Effect of Atorvastatin versus fenofibrate on lipoprotein profilers, low density lipoprotein subtraction distribution and hemorheologic parameters in type 2 diabetes mellitus with mixed hyperlipoproteinemia. Am J Cardiol. 2001;87(1):44-48.

23. Blasetto JW, Stein EA, Brown WV, Chitra R, Raza A. Efficacy of Rosuvastatin compared with other Statins at Selected starting doses in Hypercholesterolemic patients and in special population groups. Am J Cardiol. 2003;91:3C-10C.

24. Ballantyne CM, stein EA, Paoletti R, Southworth H, Blasetto JW. Efficacy of Rosuvastaitn 10 mg in patients with the metabolic syndorome. Am J Cardiol. 2003;91:25 C-28C.

25. Jayaram S, jain MM, Naikawdi AA, Gawde A, Desai A. Comparative Evaluation of the Efficacy, Safety and Tolerability of Rosuvastatin $10 \mathrm{mg}$ with Atorvastatin $10 \mathrm{mg}$ in Adult patients with hypercholesterolaemia: The First Indian Study. JIMA. 2004;102:48-52. 
TABLE I

Modified goals proposed for Asian-Indians

\begin{tabular}{|l|l|l|l|}
\hline & LDL-C & TC & Non-HDL-C \\
\hline Optimum & $<80$ & $<150$ & $<110$ \\
\hline Near or above optimal & $80-99$ & $150-169$ & $110-129$ \\
\hline Borderline high & $100-114$ & $170-184$ & $130-144$ \\
\hline High & $115-129$ & $185-199$ & $145-159$ \\
\hline Very high & $>130$ & $>200$ & $>160$ \\
\hline
\end{tabular}

TABLE II

MEAN AGE (YEARS \pm SD)

\begin{tabular}{|c|c|}
\hline Group I & $54.9 \pm 11.42$ \\
\hline Group II & $52.33 \pm 8.43$ \\
\hline
\end{tabular}

The mean age was slightly less in the group II as compared to group I

\section{TABLE III}

\section{SEXWISE DISTRIBUTION OF STUDY GROUP}

\begin{tabular}{|c|c|c|}
\hline Sex & Group I & Group II \\
\hline Male & $19(63 \%)$ & $12(40 \%)$ \\
\hline Female & $11(37 \%)$ & $18(60 \%)$ \\
\hline
\end{tabular}

TABLE IV: Lipid levels (mg/dl) and comparative percentage changes in Indian patients before and after 12 weeks of therapy.

\begin{tabular}{|c|c|c|c|c|}
\hline $\begin{array}{l}\text { Parameter } \\
(\mathrm{mg} / \mathrm{dl})\end{array}$ & $\begin{array}{l}\text { Percentage } \\
\text { Change }\end{array}$ & $\begin{array}{l}\text { Group I }(\mathrm{n}=30) \\
\{\text { Mean } \pm \text { SD }\}\end{array}$ & $\begin{array}{l}\text { Group II }(\mathrm{n}=30) \\
\{\text { Mean } \pm \text { SD }\}\end{array}$ & $\begin{array}{l}\text { Comparative } \\
\text { Difference of } \\
\text { Change between } \\
\text { Group I and II }\end{array}$ \\
\hline $\mathrm{TC}$ & $\begin{array}{l}\text { Week } 0 \\
\text { Week } 12 \\
\% \text { change } \\
\text { t value } \\
\text { p value }\end{array}$ & $\begin{array}{l}241.1 \pm 26.51 \\
173.23 \pm 17.81 \\
28.15 \\
31.48 \\
<0.0001\end{array}$ & $\begin{array}{l}242.14 \pm 32.63 \\
139.8 \pm 14.17 \\
42.26 \\
23.25 \\
<0.0001\end{array}$ & $\begin{array}{l}14.11^{*} \\
8.044 \\
<0.0001\end{array}$ \\
\hline LDL-C & $\begin{array}{l}\text { Week } 0 \\
\text { Week } 12 \\
\% \text { change } \\
\text { t value } \\
\text { p value }\end{array}$ & $\begin{array}{l}143.16 \pm 20.37 \\
99.1 \pm 8.53 \\
30.77 \\
18.29 \\
<0.0001 \\
\end{array}$ & $\begin{array}{l}147.23 \pm 29.42 \\
75.03 \pm 9.49 \\
49.03 \\
16.71 \\
<0.0001 \\
\end{array}$ & $\begin{array}{l}18.26^{*} \\
10.32 \\
<0.0001 \\
\end{array}$ \\
\hline HDL-C & $\begin{array}{l}\text { Week } 0 \\
\text { Week } 12 \\
\% \text { change } \\
\text { t value } \\
\text { p value }\end{array}$ & $\begin{array}{l}32.16 \pm 6.12 \\
42.5 \pm 5.01 \\
32.15 \\
11.49 \\
<0.0001\end{array}$ & $\begin{array}{l}31.1 \pm 5.71 \\
40.2 \pm 7.30 \\
29.26 \\
9.95 \\
<0.0001\end{array}$ & $\begin{array}{l}2.89 * \\
1.421 \\
>0.05\end{array}$ \\
\hline
\end{tabular}




\section{ORIGINAL ARTICLE}

\begin{tabular}{|l|l|l|l|l|}
\hline \hline Non-HDL-C & Week 0 & $208.66 \pm 25.43$ & $210.71 \pm 31.79$ & \\
& Week 12 & $130.86 \pm 16.73$ & $102.93 \pm 19.5$ & \\
& \% change & 37.28 & 51.15 & $13.87^{*}$ \\
& t value & 12.45 & 13.55 & 9.45 \\
& p value & $<0.0001$ & $<0.0001$ & $<0.0001$ \\
\hline TG & Week 0 & $332 \pm 89.68$ & $319.83 \pm 87.43$ & \\
& Week 12 & $163.5 \pm 45.54$ & $125 \pm 35.16$ & \\
& \% change & 50.75 & 60.91 & $10.16^{*}$ \\
& t value & 14.35 & 14.73 & 3.665 \\
& p value & $<0.0001$ & $<0.0001$ & $<0.001$ \\
\hline VLDL-C & Week 0 & $66.4 \pm 17.93$ & $63.96 \pm 17.48$ & $10.16^{*}$ \\
& Week 12 & $32.7 \pm 9.10$ & $25 \pm 7.03$ & 3.665 \\
& \% change & 50.75 & 60.91 & $<0.001$ \\
& t value & 14.35 & 14.73 & \\
& p value & $<0.0001$ & $<0.0001$ & \\
& & & & \\
\hline
\end{tabular}

*Difference in percentage change between group I and group II

\section{TABLE V}

GOALS ACHIEVED AT 12 WEEKS (NCEP ATP III GUIDELINES)

\begin{tabular}{|c|c|c|}
\hline Parameter & Group I & Group II \\
\hline TC & $29(96.6 \%)$ & $30(100 \%)$ \\
\hline LDL-C & $16(53.33 \%)$ & $30(100 \%)$ \\
\hline
\end{tabular}

\section{TABLE VI}

GOALS ACHIEVED AT 12 WEEKS (ASIAN INDIAN GUIDE LINES)

\begin{tabular}{|c|c|c|}
\hline Parameter & Group I & Group II \\
\hline TC & $2(6.66 \%)$ & $22(73.33 \%)$ \\
\hline LDL-C & $1(3.33 \%)$ & $20(66.66 \%)$ \\
\hline
\end{tabular}

